\title{
A succinct overview of virtual reality technology use in Alzheimer's disease
}

\author{
Rebeca I. García-Betances*, María Teresa Arredondo Waldmeyer, Giuseppe Fico and \\ María Fernanda Cabrera-Umpiérrez
}

Life Supporting Technologies (LifeSTech), ETSI Telecomunicaciones, Universidad Politécnica de Madrid, Madrid, Spain

OPEN ACCESS

Edited by:

Valeria Manera,

University of Nice Sophia Antipolis,

France

Reviewed by:

Pascale Piolino,

University Paris Descartes, France

Silvia Serino,

I.R.C.C.S Istituto Auxologico Italiano,

Italy

*Correspondence:

Rebeca I. García-Betances,

Life Supporting Technologies

(LifeSTech), ETSI

Telecomunicaciones, Universidad

Politécnica de Madrid, Av.

Complutense s/n, Madrid 28040,

Spain

rgarcia@/st.tfo.upm.es

Received: 30 January 2015 Accepted: 26 April 2015

Published: 12 May 2015

Citation:

García-Betances RI,

Arredondo Waldmeyer MT, Fico G and Cabrera-Umpiérrez MF (2015) A

succinct overview of virtual reality technology use in Alzheimer's

disease.

Front. Aging Neurosci. 7:80. doi: 10.3389/fnagi.2015.00080
We provide a brief review and appraisal of recent and current virtual reality (VR) technology for Alzheimer's disease (AD) applications. We categorize them according to their intended purpose (e.g., diagnosis, patient cognitive training, caregivers' education, etc.), focus feature (e.g., spatial impairment, memory deficit, etc.), methodology employed (e.g., tasks, games, etc.), immersion level, and passive or active interaction. Critical assessment indicates that most of them do not yet take full advantage of virtual environments with high levels of immersion and interaction. Many still rely on conventional 2D graphic displays to create non-immersive or semi-immersive VR scenarios. Important improvements are needed to make VR a better and more versatile assessment and training tool for AD. The use of the latest display technologies available, such as emerging head-mounted displays and 3D smart TV technologies, together with realistic multi-sensorial interaction devices, and neuro-physiological feedback capacity, are some of the most beneficial improvements this mini-review suggests. Additionally, it would be desirable that such VR applications for AD be easily and affordably transferable to in-home and nursing home environments.

Keywords: Alzheimer's disease, mild cognitive impairment, cognitive rehabilitation, virtual reality, virtual environments

\section{Virtual Reality Technology}

Recent brain plasticity theories and findings about the nervous system's ability to reconstruct cellular synapses as a result of interaction with enriched environments, have spurred new research about memory rehabilitation. Consequently, non-invasive non-pharmacological cognitive rehabilitation (CR) interventions have gained increasing attention in recent years (Cotelli et al., 2012; GarcíaBetances et al., 2014).

Since the introduction of the use of computers for psychological testing over a quarter of a century ago (Riva, 1997), several studies have emphasized the use of virtual environments (VEs) and their ecological validity for neuropsychological assessments (Spooner and Pachana, 2006; Campbell et al., 2009; Tarnanas et al., 2013; Parsons, 2015). VEs have been traditionally defined as "interactive, virtual image displays enhanced by special processing and by non-visual display modalities ... to convince users that they are immersed in a synthetic space" (Ellis, 1994). Several software technologies have been introduced into dementia care to assist patients and their families by providing memory aids and educational support (García-Betances et al., 2014). Virtual reality (VR), a recent branch of Information and Communications Technology (ICT), has been suggested for use in some areas of neuropsychology (Rizzo et al., 2001; Schultheis et al., 2002; Rizzo and Kim, 2005; Coyle et al., 2014; Lesk et al., 2014; Shah et al., 2015). Treatment of phobias, stress, and anxiety 
are characteristic examples of current VR applications in psychotherapy (Esteves and Vidal, 2004; Riva, 2005; Gregg and Tarrier, 2007; Hartanto et al., 2014; McCann et al., 2014; Paliokas et al., 2014; Smahaj and Prochazka, 2014; Fornells-Ambrojo et al., 2015). Other helpful medical uses of VR are surgical training, post-stroke intervention, musculoskeletal recovery, pain mitigation, etc. (Haque and Srinivasan, 2006; Gervasi et al., 2010; Snyder et al., 2011; Imam and Jarus, 2014; Lohse et al., 2014; Pompeu et al., 2014; Trost and Parsons, 2014; Tsoupikova et al., 2015).

Emerging VR applications today address the challenge of diagnosis and cognitive training of mild cognitive impairment (MCI) and dementia patients, concentrating on navigation and orientation, face recognition, cognitive functionality, and other instrumental activities of daily living (IADL) (Jekel et al., 2015). VR exposes cognitively impaired patients to computer-generated VEs providing a sensation of "presence" or "being there," for the patient to interact with in a multisensory fashion through quasinaturalistic real-life-like stimuli. Using several perception aspects of psychophysics, mainly visual, tactile, and kinesthetic perceptual sensations, VR offers the possibility of performing activities, tasks, and tests in a VE adaptable to various characteristics and needs of individual patients (Riva, 1997; Baus and Bouchard, 2014; GarcíaBetances et al., 2014). A characteristic of VR, very helpful for Alzheimer's disease (AD) applications, is the high interaction level that is possible to achieve in a safe VE. Depending on the specific type of VE, patients may interact from egocentric or allocentric points of view (Weniger et al., 2011). The role of egocentric and allocentric abilities in $\mathrm{AD}$ have been recently reviewed by Serino et al. (2014). The devices and stimuli used determine the level of interaction. A growing number of devices is available today for interaction (e.g., joysticks, gloves, surfaces, etc.), as well as for stimuli presentation in VEs [e.g., screens, 3D head-mounted displays (HMDs), audio headsets, speakers, etc.].

Slater et al. (2009) described the concept of the level of immersion offered by a VR system by referring to the "fidelity" to realworld sensory experience offered by the system's displays and tracking in all sensory modalities. Some features of VR systems are most significant when characterizing the immersion level (Slater et al., 2009; Ma and Zheng, 2011; Baus and Bouchard, 2014). They may be reduced to four main types: (a) number of stimulated senses, (b) quantity and level of interactions, (c) synthetic stimuli fidelity, and (d) system's ability to isolate the user from external stimuli.

Based on the above considerations, three basic levels of system immersion may be defined: (1) non-immersive; (2) semiimmersive; and (3) fully-immersive. In a non-immersive system, the patient interacts with the VE using conventional graphic workstations (PC monitor, keyboard, and mouse) (Costello, 1997; Ma and Zheng, 2011). Virtual tasks played as serious videogames even when displayed on $2 \mathrm{D}$ screens are considered for the purpose of this review as "non-immersive" VR, irrespective of the perspective used to look at the scene, whether be it an overhead view or a first-person view, commonly referred to as survey and route perspectives (Markováa et al., 2015). Other more dedicated devices, such as joysticks or gamepads may substitute the mouse. A semi-immersive VR system typically consists of more sophisticated graphics, with larger flat surface displays to present the visual VE (Ma and Zheng, 2011). A fully-immersive VE might consist of huge surrounding projection surfaces, or preferably of 3D displays, such as HMDs, that virtually place the patient inside the VE for the highest level of immersion (Costello, 1997; Baus and Bouchard, 2014).

Immersion plays a crucial role on the subjective sense of "presence." "Presence" refers to the experience of felling "being there," that is, how well the VE truly represents a real-world situation, instead of being a simple video viewing experience. "Presence" is strongly related to immersion, since increasing the immersion level induces a higher intensity of the subjective sense of "presence" experienced by the patient (Slobounov et al., 2015). The sense of presence intensity experienced by the patients while performing the required tasks, substantially affects the ensuing behavioral responses (Slobounov et al., 2015). A detailed comparative study of the effect of fully-immersive 3D stereoscopic VEs versus less immersive 2D presentations on brain functions and subsequent behavioral outcomes in VR experiments has been recently published by Slobounov et al. (2015). Health and safety implications of VR use must be taken into serious consideration (Nichols and Patel, 2002), especially when intended for AD patients. Cyber-sickness, a visually induced motion sickness (VIMS) reaction (Keshavarz et al., 2015) that could arise during or after immersion in a VE depending on the level of immersability, should be a matter of concern in clinical settings (Bohil et al., 2011). The possible occurrence and intensity of virtual reality induced sickness symptoms and effects (VRISE) appears to be dependent upon the level of immersion. Experiments have been conducted to comparatively evaluate VRISE in four VR immersion conditions: HMD, PC display, projection screen, and reality theater. In general, higher prevalence of VRISE was found the more immersive the environment is, although a high subject variability was also found (Sharples et al., 2008).

This mini-review does not pretend to be an exhaustive account of all existing applications of VR for $\mathrm{AD}$, rather, it only aims to illustrate, through representative state of the art examples of the most significant types of VR applications, the advantages of using VR for developing a new class of tools in support of the diagnostic assessment of and cognitive training in $\mathrm{AD}$.

\section{Literature Review Methodology}

The overall followed methodology may be divided into two phases: (1) literature search and selection of relevant work and (2) categorization of the selected works. The first phase consisted of an initial computer-based on-line non-systematic literature search, conducted in several high-profile databases, such as: PubMed, Web of Knowledge, IEEExplore, ScienceDirect, and Google Scholar. Only peer-reviewed journal articles in English were considered. Because of conciseness, and considering the relative novelty of the field, the search was limited to years from 2000 to the present. However, a few pre-2000 specific articles were included by reason of their outstanding relevance. VR technology studies and applications related to AD assessment and cognitive intervention were searched for using the following search terms, and combinations thereof: VR, VEs, virtual game, $\mathrm{AD}$, cognitive impairment, $\mathrm{CR}$, and cognitive training. 
References cited by the initially retrieved articles became a secondary source for manual selection, and included whenever they contributed significant new information. In addition to the most relevant recent studies of VR applications that involve $\mathrm{AD}$ patients, some others aimed at healthy elderly people were included because of their comparative value. Articles dealing with MCI patients were also included since such impairment is often a transition from healthy aging to $\mathrm{AD}$. We excluded those studies and applications in which the devices used to interact with the VE were not clearly described. A few articles whose full-text was not easily accessible were also excluded.

The second methodological phase consisted of categorizing, for later systematic study, the retrieved VR studies and application works, according to the predefined classification schematically portrayed in Figure 1.

\section{Categorization of VR Applications Used in $A D$}

The potential usefulness and exceptional opportunities of VR systems as valuable ICT tools to assess and train patients in the early stages of $\mathrm{AD}$ has been already ascertained by several studies (Schultheis et al., 2002; Gregg and Tarrier, 2007; Déjos et al., 2011; Cotelli et al., 2012; Man et al., 2012; Yamaguchi et al., 2012). For analytical purposes, it seems convenient to classify VR systems according to some functional criteria, as follows: (1) intended purpose (e.g., assessment and diagnosis, cognitive training, patient education, caregivers' training, etc.); (2) impairment feature it is focused on (e.g., spatial impairment, memory deficit, etc.); (3) methodology employed (e.g., tasks, games, or activities); (4) kind of VE (e.g., desktop, goggles-and-gloves, large screen, virtual room, etc.); and (5) type of interaction technique (e.g., fullimmersive, semi-immersive, non-immersive, and passive or active interaction, etc.). Figure 1 presents the schematic representation of such classification.
The pursuit of future advances beyond current VR applications for $\mathrm{AD}$ state of the art will benefit from a broad awareness of recent and ongoing VR developments. Such understanding essentially consists of scrutinizing and comparing design and operation specificities that aim to fulfill the intended purpose of particular $\mathrm{AD}$ applications, such as the techniques of patient interaction. A useful starting point, particularly regarding design methodology type and immersion level, is Table $\mathbf{1}$, which lists representative current VR applications for AD and briefly classifies them according to their intended purpose and interaction technique.

\section{Intended Purpose}

We have identified three main types of planned goals among the reviewed recent and current VR systems. They may be described as: (1) assessment and diagnosis; (2) cognitive training or therapy; and (3) caregivers' training. An additional purpose was proposed by Riva et al. (2009) regarding the use of VR systems for designing new tools. They developed "NeuroVR," an open-source VR platform for assessment and treatment in clinical psychology and neuroscience which allows non-expert users, such as therapists and researchers, to adapt pre-existing VEs to specific clinical or experimental settings needs (Riva et al., 2011). Intended purposes of the recent or current $\mathrm{VR}$ applications for $\mathrm{AD}$ reviewed here are indicated in Table 1.

\section{Focal Aspects}

Recent research has focused on certain specific aspects of $\mathrm{AD}$ cognitive impairment features that are generally deemed to be most relevant for VR diagnostic and training purposes. For the sake of the present mini-review, they may be roughly summarized as follows: (1) attention (Kalová et al., 2005; Anguera et al., 2013); (2) executive functions (Yeh et al., 2012; Tarnanas et al., 2013); (3) memory, comprising: non-verbal episodic memory, allocentric and egocentric spatial memory, temporal order memory, prospective memory, short-term, and working memory, etc. (Kalová et al., 2005; Burgess et al., 2006; Optale et al., 2010; Weniger et al., 2011;

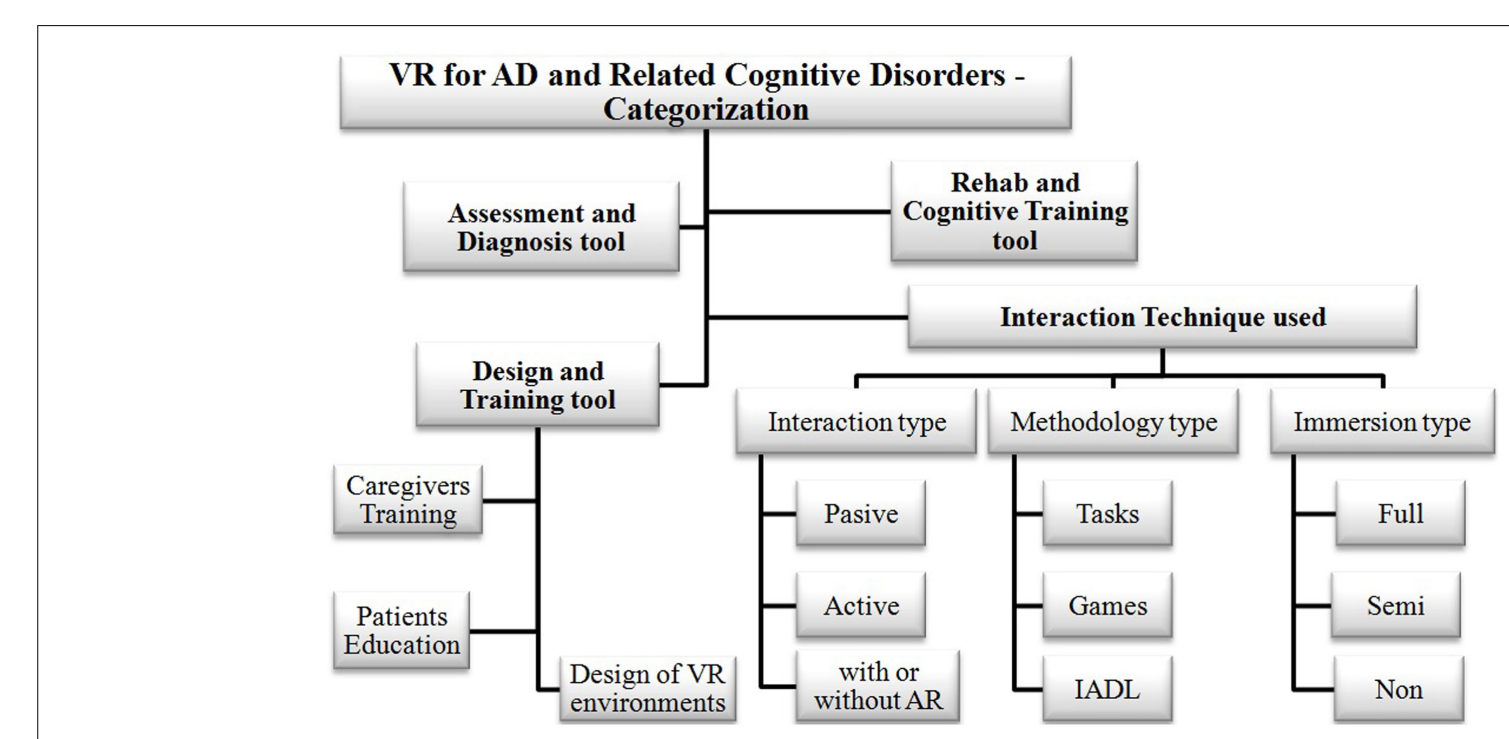

FIGURE 1 | Categorization of VR technology applications for AD 
TABLE 1 | Recent and current VR applications for AD, classified according to the kind of intended purpose and the type of methodological technique used for interaction.

\begin{tabular}{|c|c|c|c|c|c|c|c|c|c|}
\hline \multirow{3}{*}{$\begin{array}{l}\text { VR technology application } \\
\text { and/or reference }\end{array}$} & \multirow[t]{3}{*}{ Participants/users } & \multirow[t]{3}{*}{ Focus feature } & \multirow{3}{*}{$\begin{array}{l}\text { Intended } \\
\text { purpose }\end{array}$} & \multicolumn{6}{|c|}{ Interaction technique used } \\
\hline & & & & \multicolumn{3}{|c|}{ Methodology type } & \multicolumn{3}{|c|}{ Immersion type } \\
\hline & & & & Tasks & Games & IADL & Full & Semi & Non \\
\hline Kalová et al. (2005) & $\begin{array}{l}11 \text { early-AD; } 27 \text { subjective problems with memory and } \\
\text { concentration; } 10 \text { healthy controls }\end{array}$ & $\begin{array}{l}\text { Sequential ordering of places, allothetic } \\
\text { orientation, spatial navigation, non-verbal } \\
\text { episodic memory }\end{array}$ & & $x$ & & & & $x$ & $x$ \\
\hline Burgess et al. (2006) & $\begin{array}{l}1 \text { early-AD with topographical disorientation; } 4 \text { healthy } \\
\text { controls }\end{array}$ & $\begin{array}{l}\text { Allocentric spatial memory. Topographical } \\
\text { disorientation }\end{array}$ & & $x$ & & & & & $x$ \\
\hline Hort et al. (2007) & $\begin{array}{l}21 \text { probable } \mathrm{AD} ; 11 \text { amnestic } \mathrm{MCl} \text { single domain; } 18 \\
\text { amnestic } \mathrm{MCl} \text { multiple domain; } 7 \text { non-amnestic } \mathrm{MCl} ; 8 \\
\text { subjective memory complaints; } 26 \text { healthy controls }\end{array}$ & $\begin{array}{l}\text { Spatial memory. Spatial navigation: } \\
\text { allocentric and egocentric navigation }\end{array}$ & & $x$ & & & & $x$ & \\
\hline Lange et al. (2007) & 30 mild dementia Alzheimer's type; 30 healthy controls & Visuospatial and wayfinding orientation & & $x$ & & & & & $x$ \\
\hline Cushman et al. (2008) & $\begin{array}{l}12 \mathrm{MCl} ; 14 \text { early-AD; } 35 \text { young normal controls; } 26 \text { older } \\
\text { normal controls }\end{array}$ & Navigational performance & & $x$ & & & & & $x$ \\
\hline Van Schaik et al. (2008) & 30 mild to moderate dementia & Evaluation of outdoor environments & & & & $x$ & & $x$ & \\
\hline Zakzanis et al. (2009) & $\begin{array}{l}8 \text { healthy young adults; } 7 \text { older adults with psychiatric or } \\
\text { neurological disorders ( } 2 \text { with probable AD) }\end{array}$ & Spatial navigation. Spatial memory & $\begin{array}{l}\text { Assessment } \\
\text { and }\end{array}$ & $x$ & & & $x$ & & \\
\hline $\begin{array}{l}\text { Laczó et al. (2009, 2010a, 2010b, } \\
\text { 2011, 2012) }\end{array}$ & Amnestic and non-amnestic $\mathrm{MCl}$ & $\begin{array}{l}\text { Spatial navigation. Hippocampal and } \\
\text { non-hippocampal memory impairment }\end{array}$ & diagnosis & $x$ & & & & $x$ & \\
\hline Optale et al. (2010) & $\begin{array}{l}36 \text { elderly with presence of memory deficits (Verbal Story } \\
\text { Recall Test) }\end{array}$ & Improve memory functions & & $x$ & & & $x$ & & \\
\hline Weniger et al. (2011) & 29 amnestic $\mathrm{MCl} ; 29$ healthy controls & Egocentric and allocentric memory & & $x$ & & & & & $x$ \\
\hline Bellassen et al. (2012) & $\begin{array}{l}16 \text { mild AD; } 11 \text { frontotemporal lobar degeneration; } 24 \\
\text { normal aging }\end{array}$ & $\begin{array}{l}\text { Spatiotemporal navigation. Temporal order } \\
\text { memory }\end{array}$ & & $x$ & & & & & $x$ \\
\hline Nedelska et al. (2012) & $\begin{array}{l}23 \text { amnestic MCl; } 19 \text { mild and moderate AD; } 14 \text { healthy } \\
\text { controls }\end{array}$ & Allocentric spatial navigation & & $x$ & & & & $x$ & \\
\hline VREAD, Shamsuddin et al. (2012) & 31 healthy elderly and with $\mathrm{MCl}$ & $\begin{array}{l}\text { Diagnosis of } \mathrm{MCl} \text {. Cognitive performance. } \\
\text { Topographical disorientation }\end{array}$ & & $x$ & $x$ & & & & $x$ \\
\hline Yeh et al. (2012) & 60 senile dementia; 30 healthy controls & Executive functions and memory & & $x$ & & $x$ & $x$ & $x$ & \\
\hline Widmann et al. (2012) & 15 with AD; 31 healthy controls & Spatial and verbal memory & & $x$ & & & & $x$ & \\
\hline Plancher et al. (2012) & $\begin{array}{l}15 \text { amnesic } \mathrm{MCl} ; 15 \text { early to moderate AD; } 21 \text { healthy } \\
\text { older adults }\end{array}$ & Episodic memory & & $x$ & & & & & $x$ \\
\hline VR-DOT, Tarnanas et al. (2013) & $\begin{array}{l}\text { 2013: } 65 \text { amnestic MCl; } 68 \text { mild AD; } 72 \text { healthy controls. } \\
\text { 2014: } 134 \text { with MCl; } 75 \text { healthy controls }\end{array}$ & Executive function. Prospective memory & & & & $x$ & & $x$ & \\
\hline VRAM, Lee et al. (2014) & 20 amnestic MCl; 20 mild AD; 20 normal controls & Spatial working memory & & $x$ & & & & & $x$ \\
\hline Allain et al. (2014) & 24 with $A D ; 31$ healthy elderly controls & IADL functioning & & $x$ & & $x$ & & & $x$ \\
\hline Jebara et al. (2014) & 64 young adults; 64 elderly adults & Episodic memory & & $x$ & & & & $x$ & \\
\hline
\end{tabular}




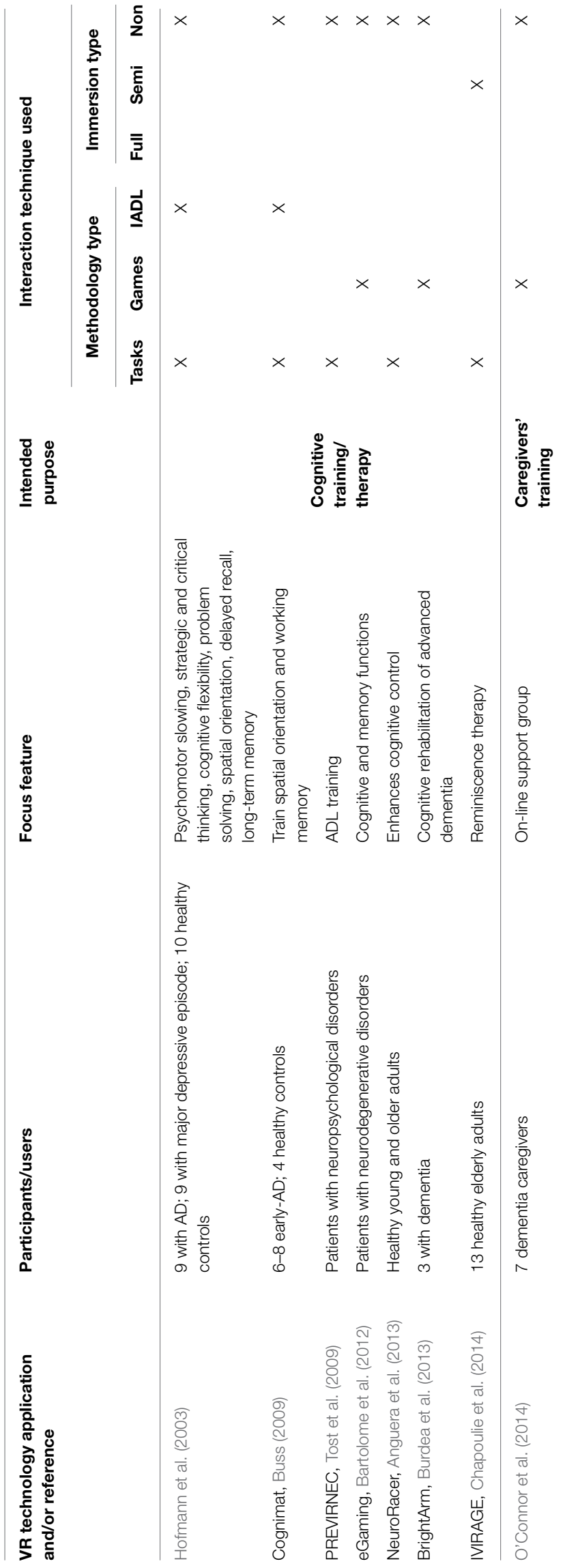

Bellassen et al., 2012; Shamsuddin et al., 2012; Yeh et al., 2012; Burdea et al., 2013; Tarnanas et al., 2013; Jebara et al., 2014; Lee et al., 2014; Serino and Riva, 2015); (4) orientation, specifically: allothetic, visuospatial, wayfinding, spatial navigation, topographical disorientation, etc. (Kalová et al., 2005; Burgess et al., 2006; Hort et al., 2007; Lange et al., 2007; Cushman et al., 2008; Zakzanis et al., 2009; Nedelska et al., 2012); and also (5) executive functions and IADL (Hofmann et al., 2003; Van Schaik et al., 2008; Buss, 2009; Yeh et al., 2012; Tarnanas et al., 2013, 2014; Allain et al., 2014; Jekel et al., 2015). The justification of the importance of these specific cognitive aspects of AD may be found in the cited references.

Some approaches look at more than one of the above mentioned aspects for better assessment. Examples of this combined focus are: Kalová et al. (2005), Burgess et al. (2006), Hort et al. (2007), Cushman et al. (2008), Laczó et al. (2009), Zakzanis et al. (2009), Weniger et al. (2011), Bellassen et al. (2012), Nedelska et al. (2012), Plancher et al. (2012), and Shamsuddin et al. (2012), likewise, a combination of more than one aspect may be used for more effective training tools (Buss, 2009; Anguera et al., 2013). Frequently, memory and attention are combined with navigation, because navigational impairment is a common manifestation of $\mathrm{AD}$ that implies disorders of spatial cognition, spatial memory, and orientation. For example, Bellassen et al. (2012) assessed temporal order memory, as acquired through active navigation (spatiotemporal navigation), to design a sensitive behavioral non-verbal marker of mild AD. Lee et al. (2014) evaluated spatial memory in amnestic MCI (aMCI) patients from results of a virtual route learning environment-labeled virtual radial arm maze (VRAM).

\section{Interaction Techniques}

User interaction with VEs and scenarios might involve several methodological modalities. It could consist of playing serious games or performing different tasks or activities (e.g., IADL). Here, we refer to "tasks" and "activities" in reference to VR systems for AD, the term "task" specifically means a particular action that is intended, designed, and established to improve a specific cognitive function, while "activities" involve performing high-level sustained cognitive actions and processes such as: eating, bathing, dressing, shopping, etc. Furthermore, the term "game" refers to activities that are defined by rules and any type of user engagement. Most current VR systems for assessment and diagnosis of $\mathrm{AD}$ are based on performing tasks, such as navigation or memorization. Moreover, current VR systems for cognitive training concentrate on performing activities that are related to IADL, such as: cooking, driving, shopping, etc. It has been recently demonstrated that the use of a familiar image-based VE can stimulate recollections of autobiographical memory in healthy elderly subjects (Benoit et al., 2015). The fact that episodic autobiographical memory is impaired in early stages of AD (Seidl et al., 2011), suggests that using such type of VR systems may be helpful for reminiscence rehabilitation of AD patients. Table 1 classifies the reviewed VR systems in terms of the methodology utilized for user interaction.

Recent progress in augmented reality (AR) indicates that this technology will probably become another useful ICT tool for AD. This form of mixed reality enhances a non-synthetic real environment by superimposing some synthetic elements into the 
users' perception of that reality (Baus and Bouchard, 2014). In contrast to VR system users, who are exposed to VEs (immersive or not), users of AR applications face real physical locations, upon which AR systems introduce additional virtual elements. Some AR applications have been developed in recent years for medically related purposes, such as phobia therapy (Botella et al., 2005; Wrzesien et al., 2014), and for assessment and treatment of psychological disorders (Giglioli et al., 2015). A few researchers have conducted appraisals of AR applications for cognitive training and rehabilitation of AD patients (Quintana and Favela, 2013). Some examples are the GenVirtual (Correa et al., 2007), BuildAR (AlKhafaji et al., 2013), and ARCube (Boletsis and Mccallum, 2014).

\section{Conclusion}

We have presented a glimpse at VR applications for diagnostic assessment and cognitive training in MCI and AD. Instead of presenting an exhaustive account of all VR applications currently available, this mini-review has focused on representative state of the art examples of the most significant types, which we have classified into specific categories to aid in their systematic scrutiny. This analysis reveals that most VR applications for AD do not offer today VEs with sufficient levels of immersion or interaction, but simpler non-immersive or semi-immersive VR scenarios.

The present general tendency to develop personalized ICTbased healthcare applications (PMC - Personalized Medicine Coalition, 2014), together with the considerable recent advances in sensor, $\mathrm{VR}$, and $3 \mathrm{D}$ technologies, highlights the urgency of continuing the improvement of existing early stage medical VR applications. The improvements should translate in better VRbased applications for AD, with more immersive VEs, based on the latest innovative technologies available (e.g., novel HMDs, 3D smart televisions, etc.). The incorporation of emerging display and interactive technologies will enable innovative designs and implementations of more effective and versatile supportive VR applications for diagnosis and cognitive training of AD patients.

We suggest that future developments of VR cognitive assessment and training applications for MCI and AD should prioritize

\section{References}

Al-Khafaji, N. J., Al Shaher, M. A., Al-Khafaji, M. J., and Ahmed Asmail, M. A. (2013). "Use buildAR to help the Alzheimer's disease patients," in The Int Conf on E-Technologies and Business on the Web (EBW2013) (Bangkok: SDIWC digital library), 280-284.

Allain, P., Foloppe, D. A., Besnard, J., Yamaguchi, T., Etcharry-Bouyx, F., Le Gall, D., et al. (2014). Detecting everyday action deficits in Alzheimer's disease using a nonimmersive virtual reality kitchen. J. Int. Neuropsychol. Soc. 20, 468-477. doi:10.1017/S1355617714000344

Anguera, J. A., Boccanfuso, J., Rintoul, J. L., Al-Hashimi, O., Faraji, F., Janowich, J., et al. (2013). Video game training enhances cognitive control in older adults. Nature 501, 97-101. doi:10.1038/nature12486

Bartolome, N. A., Zapirain, B. G., and Mendez, A. (2012). "Innovative system for cognitive brain enhancement and language disorders treatment using a virtual reality environment," in $17^{\text {th }}$ Int. Conf. CGAMES (Louisville, KY: IEEE), $120-124$.

Baus, O., and Bouchard, S. (2014). Moving from virtual reality exposure-based therapy to augmented reality exposure-based therapy: a review. Front. Hum. Neurosci. 8, 112. doi:10.3389/fnhum.2014.00112

Bellassen, V., Igloi, K., Cruz, L., Dubois, B., and Rondi-Reig, L. (2012). Temporal order memory assessed during spatiotemporal navigation as a behavioral the specificity of the particular needs of $\mathrm{AD}$ patients and their symptoms' evolution. VR platform designs must be able to incorporate emerging know-how and techniques, not only to better fulfill the intended specific purposes of VR applications for $\mathrm{AD}$, but also to equip those future applications with adequate capacity to supply assistive support to clinicians and caregivers, to significantly contribute to the improvement of the quality of life of MCI and AD patients and their families. Advances in this field should also contemplate providing easy transfer of the applications in a simple and affordable way into in-home and nursing home environments.

Furthermore, a vital feature that could make an important impact on future VR applications for AD usefulness is the capacity to timely gather and transmit relevant information (GarcíaBetances et al., 2014). Such information should consist, not only of ongoing patient performance data, but also of pertinent psychophysiological data, such as heart rate variability, respiration, ECG, EEG, etc., and any other multimodal information useful for affective (emotional) state recognition (García-Betances et al., 2015) and cognitive stress detection (McDuff et al., 2014). This data gathering feature should also include immediately accessible realtime feedback, to enable computer as well as specialist controlled intervention during the course of the session. Collected data would provide valuable up-to-date information about the patient's performance evolution, adherence to training and rehabilitation routines, as well as about synchronous physiological reactions of the patient. This feedback capacity could prove to be a valuable tool for implementing other future closed-loop applications, and also become a source of reliable data to build systematic and robust knowledge bases that are indispensable for advancing analytical research and future development.

\section{Acknowledgments}

We would like to thank the consortia of Horizon2020 EU projects "MIAMI-MD" and "PD_Manager" for their valuable contributions to the systematic conceptualization of neuropsychological knowledge used in this study.

cognitive marker for differential Alzheimer's disease diagnosis. J. Neurosci. 32, 1942-1952. doi:10.1523/JNEUROSCI.4556-11.2012

Benoit, M., Guerchouche, R., Petit, P.-D., Chapoulie, E., Manera, V., Chaurasia, G. et al. (2015). Is it possible to use highly realistic virtual reality in the elderly? A feasibility study with image-based rendering. Neuropsychiatr. Dis. Treat. 11, 557-563. doi:10.2147/NDT.S73179

Bohil, C. J., Alicea, B., and Biocca, F. A. (2011). Virtual reality in neuroscience research and therapy. Nat. Rev. Neurosci. 12, 752-762. doi:10.1038/nrn3122

Boletsis, C., and Mccallum, S. (2014). Augmented reality cube game for cognitive training: an interaction study. Stud. Health Technol. Inform. 200, 81-87. doi:10. 3233/978-1-61499-393-3-81

Botella, C. M., Juan, M. C., Baños, R. M., Alcañiz, M., Guillen, V., and Rey, B. (2005). Mixing realities? An application of augmented reality for the treatment of cockroach phobia. Cyberpsychol. Behav. 8, 162-171. doi:10.1089/cpb.2005.8.162

Burdea, G., Rabin, B., Rethage, D., Damiani, F., Hundal, J. S., and Fitzpatrick, C. (2013). "BrightArm ${ }^{\mathrm{TM}}$ therapy for patients with advanced dementia: a feasibility study," in 2013 ICVR (Philadelphia, PA: IEEE), 208-209.

Burgess, N., Trinkler, I., King, J., Kennedy, A., and Cipolotti, L. (2006). Impaired allocentric spatial memory underlying topographical disorientation. Rev. Neurosci. 17, 239-251. doi:10.1515/REVNEURO.2006.17.1-2.239

Buss, B. (2009). Virtual Reality Training System for Patients with Dementia. Zürich: ETH, Swiss Federal Institute of Technology, Institute of Neuroinformatics. 
Campbell, Z., Zakzanis, K. K., Jovanovski, D., Joordens, S., Mraz, R., and Graham, S. J. (2009). Utilizing virtual reality to improve the ecological validity of clinical neuropsychology: an FMRI case study elucidating the neural basis of planning by comparing the Tower of London with a three-dimensional navigation task. Appl. Neuropsychol. 16, 295-306. doi:10.1080/09084280903297891

Chapoulie, E., Guerchouche, R., Petit, P. D., Chaurasia, G., Robert, P., and Drettakis, G. (2014). "Reminiscence therapy using image-based rendering in VR," in 2014 IEEE VR (Minneapolis, MN: IEEE), 45-50.

Correa, A. G. D., de Assis, G. A., do Nascimento, M., Ficheman, I., and de Deus López, R. (2007). "GenVirtual: an augmented reality musical game for cognitive and motor rehabilitation," in 2007 Virtual Rehabilitation (Venice: IEEE), 1-6.

Costello, P. J. (1997). "Health and safety issues associated with virtual reality - a review of current literature," in Advisory Group on Computer Graphics, Technical Report Series. Available at: http://citeseerx.ist.psu.edu/viewdoc/download?doi= 10.1.1.6.3025\&rep=rep1\&type $=$ pdf

Cotelli, M., Manenti, R., Zanetti, O., and Miniussi, C. (2012). Non-pharmacological intervention for memory decline. Front. Hum. Neurosci. 6, 46. doi:10.3389/ fnhum. 2012.00046

Coyle, H., Traynor, V., and Solowij, N. (2014). Computerized and virtual reality cognitive training for individuals at high risk of cognitive decline: systematic review of the literature. Am. J. Geriatr. Psychiatry 23, 335-359. doi:10.1016/j. jagp.2014.04.009

Cushman, L. A., Stein, K., and Duffy, C. J. (2008). Detecting navigational deficits in cognitive aging and Alzheimer disease using virtual reality. Neurology 71, 888-895. doi:10.1212/01.wnl.0000326262.67613.fe

Déjos, M., Sauzéon, H., Falière, A., and N'Kaoua, B. (2011). Naturalistic assessment of spatial cognition disorders in Alzheimer's disease using virtual reality. Ann. Phys. Rehabil. Med. 54, e90. doi:10.1016/j.rehab.2011.07.696

Ellis, S. R. (1994). What are virtual environments? IEEE Comput. Graph. Appl. 14, 17-22. doi:10.1109/38.250914

Esteves, R., and Vidal, L. (2004). The acceptance of virtual reality devices for cognitive rehabilitation: a report of positive results with schizophrenia. Comput. Methods Programs Biomed. 73, 173-182. doi:10.1016/S0169-2607(03)00066-X

Fornells-Ambrojo, M., Freeman, D., Slater, M., Swapp, D., Antley, A., and Barker, C. (2015). How do people with persecutory delusions evaluate threat in a controlled social environment? A qualitative study using virtual reality. Behav. Cogn. Psychother. 43, 89-107. doi:10.1017/S1352465813000830

García-Betances, R., Fico, G., Salvi, D., OTTaviano, M., and Arredondo, M. T. (2015). On the convergence of affective and persuasive technologies in computer-mediated health-care systems. Human Technol. (in press).

García-Betances, R., Jiménez-Mixco, V., Arredondo, M. T., and CabreraUmpiérrez, M. F. (2014). Using virtual reality for cognitive training of the elderly. Am. J. Alzheimers Dis. Other Demen. 30, 49-54. doi:10.1177/ 1533317514545866

Gervasi, O., Magni, R., and Zampolini, M. (2010). Nu! Reha VR: virtual reality in neuro tele-rehabilitation of patients with traumatic brain injury and stroke. Virtual Real. 14, 131-141. doi:10.1007/s10055-009-0149-7

Giglioli, I. A. C., Pallavicini, F., Pedroli, E., Serino, S., and Giuseppe Riva, G. (2015). Augmented reality: a brand new challenge for the assessment and treatment of psychological disorders, review article. Comput. Math. Methods Med. Article ID: 862942 (in press).

Gregg, L., and Tarrier, N. (2007). Virtual reality in mental health: a review of the literature. Soc. Psychiatry Psychiatr. Epidemiol. 42, 343-354. doi:10.1007/ s00127-007-0173-4

Haque, S., and Srinivasan, S. (2006). A meta-analysis of the training effectiveness of virtual reality surgical simulators. IEEE Trans. Inf. Technol. Biomed. 10, 51-58. doi:10.1109/TITB.2005.855529

Hartanto, D., Kampmann, I. L., Morina, N., Emmelkamp, P. G. M., Neerincs, M. A., and Brinkman, W. P. (2014). Controlling social stress in virtual reality environments. PLoS ONE 9:e92804. doi:10.1371/journal.pone.0092804

Hofmann, M., Rosler, A., Schwarz, W., Muller-Spahn, F., Krauchi, K., Hock, C., et al. (2003). Interactive computer-training as a therapeutic tool in Alzheimer's disease. Compr. Psychiatry 44, 213-219. doi:10.1016/ S0010-440X(03)00006-3

Hort, J., Laczo, J., Vyhnalek, M., Bojar, M., Bures, J., and Vlcek, K. (2007). Spatial navigation deficit in amnestic mild cognitive impairment. Proc. Natl. Acad. Sci. U.S.A. 104, 4042-4047. doi:10.1073/pnas.0611314104

Imam, B., and Jarus, T. (2014). Virtual reality rehabilitation from social cognitive and motor learning theoretical perspectives in stroke population. Rehabil. Res. Pract. 2014, 540-594. doi:10.1155/2014/594540
Jebara, N., Orriols, E., Zaoui, M., Berthoz, A., and Piolino, P. (2014). Effects of enactment in episodic memory: a pilot virtual reality study with young and elderly adults. Front. Aging Neurosci. 6, 338. doi:10.3389/fnagi.2014.00338

Jekel, K., Damian, M., Wattmo, C., Hausner, L., Bullock, R., Connelly, P. J., et al. (2015). Mild cognitive impairment and deficits in instrumental activities of daily living: a systematic review. Alzheimers Res. Ther. 7, 17-20. doi:10.1186/ s13195-015-0099-0

Kalová, E., Vlček, K., Jarolímová, E., and Bureš, J. (2005). Allothetic orientation and sequential ordering of places is impaired in early stages of Alzheimer's disease: corresponding results in real space tests and computer tests. Behav. Brain Res. 159, 175-186. doi:10.1016/j.bbr.2004.10.016

Keshavarz, B., Riecke, B. E., Hettinger, L. J., and Campos, J. L. (2015). Vection and visually induced motion sickness: how are they related? Front. Psychol. 6, 472. doi:10.3389/fpsyg.2015.00472

Laczó, J., Andel, R., Vlcek, K., Matoska, V., Vyhnalek, M., Tolar, M., et al. (2011). Spatial navigation and APOE in amnestic mild cognitive impairment. Neurodegener. Dis. 8, 169-177. doi:10.1159/000321581

Laczó, J., Andel, R., Vlcek, K., Vyhnalek, M., Magerova, H., Varjassyova, A., et al. (2010a). Spatial navigation deficits predict Alzheimer's disease in patients with amnestic mild cognitive impairment: a 3-year follow-up study. Eur. J. Neurol. 17,44 .

Laczó, J., Andel, R., Vyhnalek, M., Vlcek, K., Magerova, H., Varjassyova, A., et al. (2010b). Human analogue of the Morris water maze for testing subjects at risk of Alzheimer's disease. Neurodegener. Dis. 7, 148-152. doi:10.1159/000289226

Laczó, J., Andel, R., Vyhnalek, M., Vlcek, K., Magerova, H., Varjassyova, A., et al. (2012). From Morris water maze to computer tests in the prediction of Alzheimer's disease. Neurodegener. Dis. 10, 153-157. doi:10.1159/000333121

Laczó, J., Vlček, K., Vyhnálek, M., Vajnerová, O., Ort, M., Holmerová, I., et al. (2009). Spatial navigation testing discriminates two types of amnestic mild cognitive impairment. Behav. Brain Res. 202, 52-59. doi:10.1016/j.bbr.2009.03. 041

Lange, B. S., Rizzo, A., Astur, R., and Parsons, T. (2007). Virtual reality visuospatial and wayfinding assessment for mild dementia of the Alzheimer's type. Alzheimers Dementia 3, S135. doi:10.1016/j.jalz.2007.04.178

Lee, J. Y., Kho, S., Yoo, H. B., Park, S., Choi, J. S., Kwon, J. S., et al. (2014). Spatial memory impairments in amnestic mild cognitive impairment in a virtual radial arm maze. Neuropsychiatr. Dis. Treat. 10, 653-660. doi:10.2147/NDT.S58185

Lesk, V. E., Shamsuddin, S. N. W., Elizabeth, R., Walters, E. R., and Ugail, H. (2014), Using a virtual environment to assess cognition in the elderly. Virtual Real. 18, 271-279. doi:10.1007/s10055-014-0252-2

Lohse, K. R., Hilderman, C. G. E., Cheung, K. L., Tatla, S., and Van der Loos, H. F M. (2014). Virtual reality therapy for adults post-stroke: a systematic review and meta-analysis exploring virtual environments and commercial games in therapy. PLoS ONE 9:e93318. doi:10.1371/journal.pone.0093318

Ma, M., and Zheng, H. (2011). Virtual reality and serious games in healthcare. Adv. Comput. Intell. Paradigms Healthcare 6, 169-192. doi:10.1007/ 978-3-642-17824-5 9

Man, D. W. K., Chung, J. C. C., and Lee, G. Y. Y. (2012). Evaluation of a virtual reality-based memory training programme for Hong Kong Chinese older adults with questionable dementia: a pilot study. Int. J. Geriatr. Psychiatry 27, 513-520. doi:10.1002/gps.2746

Markováa, H., Laczóa, J., Andeld, R., Horta, J., and Vlcek, K. (2015). Perspective taking abilities in amnestic mild cognitive impairment and Alzheimer's disease. Behav. Brain Res. 281, 229-238. doi:10.1016/j.bbr.2014.12.033

McCann, R. A., Armstrong, C. M., Skopp, N. A., Edwards-Stewart, A., Smolenski, D. J., June, J. D., et al. (2014). Virtual reality exposure therapy for the treatment of anxiety disorders: an evaluation of research quality. J. Anxiety Disord. 28, 625-631. doi:10.1016/j.janxdis.2014.05.010

McDuff, D., Gontarek, S., and Picard, R. (2014). "Remote measurement of cognitive stress via heart rate variability," in 36th Annual International Conference of the IEEE Engineering in Medicine and Biology Society (EMBC), 26-30 Aug. 2014 (Chicago, IL: IEEE), 2957-2960. doi:10.1109/EMBC.2014.6944243

Nedelska, Z., Andel, R., Laczo, J., Vlcek, K., Horinek, D., Lisy, J., et al. (2012). Spatial navigation impairment is proportional to right hippocampal volume. Proc. Natl. Acad. Sci. U.S A. 109, 2590-2594. doi:10.1073/pnas.1121588109

Nichols, S., and Patel, H. (2002). Health and safety implications of virtual reality: a review of empirical evidence. Appl. Ergon. 33, 251-271. doi:10.1016/ S0003-6870(02)00020-0

O'Connor, M. F., Arizmendi, B. J., and Kaszniak, A. W. (2014). Virtually supportive a feasibility pilot study of an online support group for dementia caregivers 
in a 3D virtual environment. J. Aging Stud. 30, 87-93. doi:10.1016/j.jaging.2014. 03.001

Optale, G., Urgesi, C., Busato, V., Marin, S., Piron, L., Priftis, K., et al. (2010). Controlling memory impairment in elderly adults using virtual reality memory training: a randomized controlled pilot study. Neurorehabil. Neural Repair 24, 348-357. doi:10.1177/1545968309353328

Paliokas, I., Tsakiris, A., Vidalis, A., and Tzovaras, D. (2014). "Sense of presence and metacognition enhancement in virtual reality exposure therapy in the treatment of social phobias and the fear of flying," in Proceedings of the VAMR 2014 (Springer International Publishing), 316-328. doi:10.1007/ 978-3-319-07464-1_30

Parsons, T. D. (2015). "Ecological validity in virtual reality-based neuropsychological assessment," in Encyclopedia of Information Science and Technology, Third Edition, ed. M. Khosrow-Pour (Hershey, PA: Information Science Reference), 1006-1015. doi:10.4018/978-1-4666-5888-2.ch095

Plancher, G., Tirard, A., Gyselinck, V., Nicolas, S., and Piolino, P. (2012). Using virtual reality to characterize episodic memory profiles in amnestic mild cognitive impairment and Alzheimer's disease: influence of active and passive encoding. Neuropsychologia 50, 592-602. doi:10.1016/j.neuropsychologia.2011. 12.013

PMC - Personalized Medicine Coalition. (2014). The Case for Personalized Medicine, 4th Edn. Available at: http://www.personalizedmedicinecoalition.org/ Resources/Publications

Pompeu, J. E., Alonso, T. H., Masson, I. B., Pompeu, S. M. A. A., and Torriani-Pasin, C. (2014). The effects of virtual reality on stroke rehabilitation: a systematic review. Motricidade 10, 111-122. doi:10.6063/motricidade.10(4)0.3341

Quintana, E., and Favela, J. (2013). Augmented reality annotations to assist persons with Alzheimer's and their caregivers. Pers. Ubiquitous Comput. 17, 1105-1116. doi:10.1007/s00779-012-0558-6

Riva, G. (1997). Virtual reality as assessment tool in psychology. Stud. Health Technol. Inform. 44, 71-79. doi:10.3233/978-1-60750-888-5-71

Riva, G. (2005). Virtual reality in psychotherapy: review. Cyberpsychol. Behav. 8, 220-240. doi:10.1089/cpb.2005.8.220

Riva, G., Carelli, L., Gaggioli, A., Gorini, A., Vigna, C., Corsi, R., et al. (2009). NeuroVR 1.5-A free virtual reality platform for the assessment and treatment. Stud. Health Technol. Inform. 142, 268-270. doi:10.3233/978-1-58603-964-6-268

Riva, G., Gaggioli, A., Grassi, A., Raspelli, S., Cipresso, P., Pallavicini, F., et al. (2011). NeuroVR 2 - a free virtual reality platform for the assessment and treatment in behavioral health care. Stud. Health Technol. Inform. 163, 493-495. doi:10.3233/978-1-60750-706-2-493

Rizzo, A., and Kim, G. J. (2005). ASWOT analysis of the field of virtual reality rehabilitation and therapy. Presence (Camb) 14, 119-146. doi:10.1162/ 1054746053967094

Rizzo, A. A., Buckwalter, J. G., McGee, J., Bowerly, T., van der Zaag, C., Neumann, U., et al. (2001). Virtual environments for assessing and rehabilitating cognitive/functional performance: a review of project's at the USC Integrated Media Systems Center. Presence 10, 359-374. doi:10.1162/ 1054746011470226

Schultheis, M. T., Himelstein, J., and Rizzo, A. R. (2002). Virtual reality and neuropsychology: upgrading the current tools. J. Head Trauma Rehabil. 17, 379-394. doi:10.1097/00001199-200210000-00002

Seidl, U., Lueken, U., Thomann, P. A., Geider, J., and Schroder, J. (2011). Autobiographical memory deficits in Alzheimer's disease. J. Alzheimers Dis. 27, 567-574. doi:10.3233/JAD-2011-110014

Serino, S., Pietro Cipresso, P., Morganti, F., and Riva, G. (2014). The role of egocentric and allocentric abilities in Alzheimer's disease: a systematic review. Ageing Res. Rev. 16, 32-44. doi:10.1016/j.arr.2014.04.004

Serino, S., and Riva, G. (2015). How different spatial representations interact in virtual environments: the role of mental frame syncing. Cogn. Process. 16, 191-201. doi:10.1007/s10339-015-0646-4

Shah, L. B. I., Torres, S., Kannusamy, P., Chng, C. M. L., He, H. G., and KlaininYobas, P. (2015). Efficacy of the virtual reality-based stress management program on stress-related variables in people with mood disorders: the feasibility study. Arch. Psychiatr. Nurs. 29, 6-13. doi:10.1016/j.apnu.2014.09.003

Shamsuddin, S. N. W., Ugail, H., Lesk, V., and Walters, E. (2012). "VREAD: a virtual simulation to investigate cognitive function in the elderly," in Int Conf Cyberworlds, Darmstadt. doi:10.1109/CW.2012.37

Sharples, S., Cobb, S., Moody, A., and Wilson, J. R. (2008). Virtual reality induced symptoms and effects (VRISE): comparison of head mounted display (HMD), desktop and projection display systems. Displays 29, 58-69. doi:10.1016/j.displa. 2007.09.005

Slater, M., Lotto, B., Arnold, M. M., and Sanchez-Vives, M. V. (2009). How we experience immersive virtual environments: the concept of presence and its measurement. Annuario de Psicología 40, 193-210.

Slobounov, S. M., Ray, W., Johnson, B., Slobounov, E., and Newell, K. M. (2015). Modulation of cortical activity in 2D versus 3D virtual reality environments: an EEG study. Int. J. Psychophysiol. 95, 254-260. doi:10.1016/j.ijpsycho.2014.11.003

Smahaj, J., and Prochazka, R. (2014). Virtual reality as alternative for anxiety disorders treatment. Cesk. Psychol. 58, 571-579. doi:10.1002/da.20734

Snyder, C. W., Vandromme, M. J., Tyra, S. L., Porterfield, J. R., Clements, R. H., and Hawn, M. T. (2011). Effects of virtual reality simulator training method and observational learning on surgical performance. World J. Surg. 35, 245-252. doi:10.1007/s00268-010-0861-1

Spooner, D. M., and Pachana, N. A. (2006). Ecological validity in neuropsychological assessment: a case for greater consideration in research with neurologically intact population. Arch. Clin. Neuropsychol. 21, 327-337. doi:10.1016/j.acn.2006. 04.004

Tarnanas, I., Schlee, W., Tsolaki, M., Müri, R., Mosimann, U., and Nef, T. (2013). Ecological validity of virtual reality daily living activities screening for early dementia: longitudinal study. JMIR Serious Games 1, e1. doi:10.2196/games. 2778

Tarnanas, I., Tsolaki, M., Nef, T., Müri, R. M., and Mosimann, U. P. (2014). Can a novel computerized cognitive screening test provide additional information for early detection of Alzheimer's disease? Alzheimers Dement. 10, 790-798. doi:10.1016/j.jalz.2014.01.002

Tost, D., Grau, S., Ferre, M., Garcia, P., Tormos, J. M., Garcia, A., et al. (2009). "PREVIRNEC: a cognitive telerehabilitation system based on virtual environments," in Int Conf Vir Rehab (Haifa: IEEE), 87-93. doi:10.1109/ICVR.2009.5174211

Trost, Z., and Parsons, T. D. (2014). Beyond distraction: virtual reality graded exposure therapy as a treatment for pain-related fear and disability in chronic pain. J. Appl. Biobehav. Res. 19, 106-126. doi:10.1111/jabr.12021

Tsoupikova, D., Stoykov, N. S., Corrigan, M., Thielbar, K., Vick, R., Li, Y., et al. (2015). Virtual immersion for post-stroke hand rehabilitation therapy. Ann. Biomed. Eng. 43, 467-477. doi:10.1007/s10439-014-1218-y

Van Schaik, P., Martyr, A., Blackman, T., and Robinson, J. (2008). Involving persons with dementia in the evaluation of outdoor environments. Cyberpsychol. Behav. 11, 415-424. doi:10.1089/cpb.2007.0105

Weniger, G., Ruhleder, M., Lange, C., Wolf, S., and Irle, E. (2011). Egocentric and allocentric memory as assessed by virtual reality in individuals with amnestic mild cognitive impairment. Neuropsychologia 49, 518-527. doi:10.1016/j. neuropsychologia.2010.12.031

Widmann, C. N., Beinhoff, U., and Riepe, M. W. (2012). Everyday memory deficits in very mild Alzheimer's disease. Neurobiol. Aging 33, 297-303. doi:10.1016/j. neurobiolaging.2010.03.012

Wrzesien, M., Alcañiz, M., Botella, C., Burkhardt, J.-M., Breton, L. J., and Rodríguez, O. A. (2014). A pilot evaluation of a therapeutic game applied to small animal phobia treatment. Seripus Games Dev. Appl. 8778, 10-20. doi:10.1007/ 978-3-319-11623-5_2

Yamaguchi, T., Foloppe, D. A., Richard, P., Richard, E., and Allain, P. (2012). A dualmodal virtual reality kitchen for (Re)learning of everyday cooking activities in Alzheimer's disease. Precence 21, 43-57. doi:10.1162/PRES a 00080

Yeh, S. C., Tsai, C. F., Chen, Y. C., and Rizzo, A. (2012). "An innovative virtual reality system for mild cognitive impairment: diagnosis and evaluation," in IEEE EMBS Conf IECBES (Langkawi: IEEE), 23-27.

Zakzanis, K., Quintin, G., Graham, S., and Mraz, R. (2009). Age and dementia related differences in spatial navigation within an immersive virtual environment. Med. Sci. Monit. 15, CR140-CR150.

Conflict of Interest Statement: The authors declare that the research was conducted in the absence of any commercial or financial relationships that could be construed as a potential conflict of interest.

Copyright (c) 2015 García-Betances, Arredondo Waldmeyer, Fico and CabreraUmpiérrez. This is an open-access article distributed under the terms of the Creative Commons Attribution License (CC BY). The use, distribution or reproduction in other forums is permitted, provided the original author(s) or licensor are credited and that the original publication in this journal is cited, in accordance with accepted academic practice. No use, distribution or reproduction is permitted which does not comply with these terms. 